\title{
The Influence of Company Size on Energy Management Systems Adoption: A System Dynamics Model
}

\author{
Camila Reis ${ }^{1}$ \\ camilacompagnoni@gmail.com | (D) 0000-0003-2182-4204 \\ Lívia Benvenutti ${ }^{1}$ \\ lmmbenvenutti@gmail.com | (D) 0000-0002-4543-4449 \\ Lucila Campos ${ }^{1}$ \\ lucila.campos@ufsc.br| (D) 0000-0002-1610-7617 \\ Maurício Uriona ${ }^{1}$ \\ m.uriona@ufsc.br| (1D 0000-0002-1174-4828
}

\begin{abstract}
Isomorphism can be understood as the process that leads one population to resemble another in the same environmental conditions. Isomorphic pressures are felt differently depending on the size of the organization and can disturb the adoption of Energy Management Systems, such as ISO 50001. Given institutional differences, how can government's coercive pressures impact the spread of ISO 50001 in each size group? To what extent can they influence the overall spread of certification? This article applies the Bass diffusion model to assess the ISO 50001 certification over the 2016-2040 period, using a system dynamics modeling approach. It proposes an extension of the diffusion model related to market stakeholder pressure, based on institutional theory. The results showed that financial and fiscal incentives provided the most significant impact on the overall number of certified industries. Large companies are the most relevant segment for certification without additional policies, while smaller ones benefit significantly from incentive programs. This study reinforces the relevance that stakeholders have in promoting greener standards and initiatives, and offers useful lessons on the dynamics of adopting energy management systems.
\end{abstract}

\section{KEYWORDS}

Energy Management Systems, ISO 50001, Bass Diffusion Model, System Dynamics

${ }^{1}$ Universidade Federal de Santa Catarina, Florianópolis, SC, Brasil

Received: 09/06/2019.

Revised: $12 / 23 / 2019$.

Accepted: 02/29/2020.

Published Online: 08/10/2020.

DOI: http://dx.doi.org/10.15728/bbr.2020.17.5.6 


\section{INTRODUCTION}

World energy demand will grow for the next few years, with significant participation in this growth by non-OECD countries. In the Brazilian case, the Energy Research Company (in portuguese: Empresa de Pesquisa Energética, EPE) estimates an increase in energy consumption at an average annual rate of $2.5 \%$ between 2019 and 2029, with the industrial sector receiving prominence in final energy consumption (behind only the energy sector). It implies an increase from an energy consumption level of 83 million tons of oil equivalent (toe) in 2019 to 108 million toe in 2029 (Brasil, 2019). Growth in energy consumption reflects increased greenhouse gas (GHG) emissions, contributing to global warming. Globally, energy consumption in the industrial and commercial sectors accounts for nearly 40\% of global GHG emissions (McKane et al., 2017), and as a result, several nations have begun to focus on conservation and energy efficiency as a way to reduce these emissions. This context demonstrates that reducing energy consumption in these sectors is thus one key strategy for countries to achieve their nationally determined contribution (NDC) targets, outlined in the Conference of the Parties (COP), held in United Nations Climate Change conferences.

As for climate change, for the industrial sector to achieve its mitigation potential, the lack of human and institutional capacities to encourage management decisions is a primary barrier to energy efficiency that must be circumvented (McKane et al., 2017). Recent research supported by the World Bank has shown the potential for energy efficiency in Brazilian energy-intensive industrial segments of around 5 million toe (Brasil, 2019). Energy Management System (EnMS) can be a facilitator in enhancing energy performance continuously. The International Organization for Standardization (ISO) deals with such management system standards and has membership over 160 national standards bodies.

Created in 2011, ISO 50001 has been widely adopted as a national and regional standard. After just the first year of its launch, ISO 50001 presented a global growth of over $300 \%$, from the 459 organizations certified in 2011, to 2236 in 2012 (ISO, 2017). By the end of 2016, there were more than twenty thousand certifications (ISO, 2017). The standard can potentially affect $60 \%$ of the annual world energy consumption (ISO, 2011). This potential has provided an increasing interest by the scientific community. Also, by 2030 , if $50 \%$ of the industrial sector submits to ISO 50001 management, energy savings could reach an equivalent of removing 210 million passenger vehicles from the roads (McKane et al., 2017). The pursuit of energy intensity reduction reflects, however, beyond environmental objectives, assistance to reduce costs and increase the competitiveness of industrial facilities. In relation to the factors that lead to the diffusion of ISO 50001 in different regions of the world, some authors point out space in the literature for future more detailed investigations considering countries with fewer certifications (like Brazil), and the factors that influence the dissemination of this EnMS (Lira, Salgado \& Beijo, 2019) .

Even though ISO 50001 is a voluntary standard, regional, or national program, supporting it can be mandatory. Public programs in support of EnMS implementation help organizations overcome barriers to efficiency improvement with tax incentives, regulatory mechanisms, training, recognition programs and so on. Some national policies and programs have boosted the uptake of its implementation (McKane et al., 2017). These programs and policies are part of stakeholderpressure exerted on organizations, which ultimately influence their managerial decisions following an isomorphism perspective (DiMaggio \& Powell, 1983). 
The concept of institutional theory concerns itself with how groups and organizations best ensure its position through the legitimacy of organizational practices. The institutional environment exerts social and cultural pressures on practices and organizational structures. These pressures can be identified as laws, regulatory frameworks, and practices of the institutional environment or corporate practices-either internally or externally, formally or informally. Institutional theory has been accepted as a justification for actions, structure, and practices of institutions. Such a theory considers three main drivers related to institutional isomorphism, by which institutional changes can occur through coercive, mimetic, and/or normative pressures (DiMaggio \& Powell, 1983).

The transmission of the coercive isomorphism way is the result of formal and informal pressures practiced by organizations they depend on and by cultural expectations of society. These pressures are extremely important (Kilbourne, Beckmann, \& Thelen, 2002), and the most obvious when it comes to environmental issues (Zhu \& Sarkis, 2007). Coercive is associated with government agencies and regulatory bodies, through of mandatory regulations. This pressure may also arise from the need to meet tax and accounting regulations (Wu, Daniel, Hinton, \& Quintas, 2013). These fines, penalties, and even legal sanctions, reflect over the organization's public image and customer relations (Sarkis et al., 2010). Therefore, this isomorphism can beunderstood as the main reason why organizations implement proactive green strategies.

The mimetic isomorphism occurs by imitation of actions of successful competitors, as an attempt to replicate their path to success (Sarkis, Zhu, \& Lai, 2011). It brings a simple thought, i.e., to follow actions of successful competitors is to also be successful. When a firm is in an uncertain situation, for example, in a rapid technological or market change, mimetic isomorphism can maintain competitiveness and avoid or minimize an unexpected adverse result (Yang \& Hyland, 2012). In some cases, as in an environmental context, market leaders follow actions far beyond compliance, which ends up raising the standard for the other competitors in their market field. There are some mechanisms by which one organization can model itself by another, such as, for example, recruiting employees from other firms, consultants, and participation in industrial associations (Wu et al., 2013).

In turn, normative isomorphism refers to the pursuit of compliance by organizationin order to be perceived as legitimatly participating in actions. Normative pressures arise from the interaction between firms, as they reinforce and disseminate behavioral norms. The main way in which normative isomorphism occurs is through professionalization (Masocha \& Fatoki, 2018), or by social obligation (Pham, 2015). The normative pressures are related to awareness of the environment (Ball \& Craig, 2010; Zhu \& Sarkis, 2007). For example, community groups can influence the regulatory system, media, and consumer buying patterns, enabling organizations to adapt in order to stay in the market (Henriques \& Sadorsky, 2013). If organizations have a significant number of employees concerned with environmental issues, the normative pressure is also observed (Pham, 2015).

All institutional pressures (normative, coercive, and mimetic) have the strength to influence an organization into adopting green supply chain management practices (Zhu, Sarkis, \& Lai, 2008). Several pieces of research have examined the influence of institutional pressures by different stakeholders on environmental management initiatives (Baek, 2017; Nicole, Irene, \& Perry, 2010; Pham, 2015; Sarkis, Gonzalez-Torre, \& Adenso-Diaz, 2010). In the eyes of external stakeholders, a certification can contribute to strengthening the legitimacy of organizations (Testa, Boiral, \& Iraldo, 2018). Institutional and market pressures have the power to influence an organization into adopting green supply chain management practices or certifiable systems (Testa et al., 2018; Zhu, Sarkis, \& Lai, 2008). In this way, the institutional theory can be an 
BBR

17

582

organizational lens in order to study the transition between green supply chains to low-carbon supply chain, where ISO 50001 fits in (Jabbour et al., 2017).

Several countries have national policies supporting industrial energy management and efficiency. Programs such as "Financial assistance for energy efficiency and EnMS Implementation" (FEEM) can be seen in countries such as Canada, China, Denmark, Germany, Japan, Netherlands, and others. "Training for Energy Managers" (TREM) and "Recognition Program" (RP) can also be seen in those countries and others, such as the US, Sweden, Ireland. There are also tax policies (incentives and/or penalties) programs and those related to "Target-setting Agreements with industries" (TSA).

In Brazil, however, none of these national programs are evident and the ISO 50001 certification has been spreading timidly. Even though a few industries are implementing the standard, the lack of national policies seems to compromise its diffusion. While some countries such as China, Italy, the United Kingdom, and Germany have ended 2016 with 1015, 1415, 2829 and 9024 certifications, respectively, Brazil has finished the same year with 22 (ISO, 2017). This positions ISO 50001 not only as a key component to increasing efficiency but also to experience institutional pressures. If NDCs arethe target, new government policies and strategies will be needed for energy and low carbon efficiency achievements (Jabbour et al., 2017). By 2030, Brazil has set a target that they will have 43\% GHG emissions (compared to 2005 level) (MMA, 2016). The government should act as a protagonist with incentive policies (as Tax Polices, Financial assistance for Energy Efficiency/ EnMS implementation, Training for Energy Managers or Recognition Program), sectorial targets (as Target-Setting Agreements with industry) or even proposing mandatory policies for energy management systems.

Such as in ISO 14001 certification, the ISO 50001 certification implies significant costs. These costs might be related to new management system creation or modification of existing materials and equipment, documentation, training, environmental consultants and third-party certifications auditing (Darnall, 2006; Kanneganti et al., 2017). The potential for energy efficiency improvements through the adoption of energy management practices depends primarily on a company's size, type of production, and energy intensity (Jovanović \& Filipović, 2016). In this context, companies with superior financial performance are more likely to seek and obtain management systems' certifications (Baek, 2017). In the Brazilian scenario, research suggests that small companies are less likely to seek ISO 14001 (Oliveira \& Serra, 2010; Pombo \& Magrini, 2008) because the benefits of this certification may be less expressive in this sector if we consider the return on the costs of certification (Campos, 2012). Furthermore, small andmedium firms are less likely to adopt a standard when there is an absence or low level of coercive pressures such as tax and financial incentives from the government (Baek, 2017).

From the above, this study aims to investigate the strength of different national policies and the effect incentives may have on the ISO 50001 diffusion. Coercive pressures have been specially attributed of enhancing the adoptions of environmental practices (Phan \& Baird, 2015). Thus, assuming different adoption characteristics (pattern), how will different coercive pressures influence ISO 50001 diffusion in each segment size of organizations? To what extent may these pressures impact overall certification uptake? To our knowledge, no scholarship has investigated how stakeholders' pressures may influence the spread of EnMS over different organization sizes. Understanding the way they may be affected by different policies and programs pressures can benefit both policymakers and industry. 
For this purpose, we developed a system dynamic model based on the theory of Bass Diffusion Model (BM) to assess the diffusion of EnMS - ISO 50001 certification. Some extensions to the model were considered, such as the inclusion of another diffusion force, besides innovator and imitator factor, named the market relation force. Stella ${ }^{\oplus}$ Software from Isee System was used to calibrate factors using the metric sum of square error (SSE) of value between the total historical number of ISO 9001 certified industries and model production for the period 1997-2016. Based on institutional theory literature, some assumptions were made as to the strength (and to which extent) these forces have in influencing different organization sizes, through simulations, also with the Stella ${ }^{\oplus}$ software. Furthermore, the model allowed an assessment of some policies inducing the certification uptake.

We note that financial and tax incentives have a more significant impact on the number of certified industries. In contrast to large industries, small and medium size firms benefit from the additional policies tested in the model. In the scientific field, this study offers useful information on the use of energy management systems in different sizes of industry.. This study provides implications for both industry and government to promote the ISO 50001 standard among organizations, reinforcing the relevance of stakeholders for promoting greener initiatives. The results are useful for policy makers on different types of policies, incentives and strategies - not observed in Brazil until now - that helps in the diffusion of energy management systems, contributing to decision making.

\section{METHOD}

For the investigation of ISO 50001 diffusion in Brazil, we use BM theory (Bass, 1969) through a system dynamics modeling approach (see Sterman, Oliva, Linderman, and Bendoly (2015)). Some extensions were considered, as presented hereafter. Also, some policy scenarios are assessed to investigate the potential they have on promoting the uptake of this EnMS by organization size. Hence,the research method has been divided into three subsections. Subsection 2.1 briefly presents the description of BM. Subsection 2.2 presents the procedures undertaken for the model development, which includes the assumptions considered and the estimates parameters. Subsection 2.3 presents the scenario descriptions considered for analysis and its implications in the model.

\subsection{BASS DIFFUSION MODEL (BM)}

By definition, diffusion models seek to represent the growth of a particular category of products (Mahajan, Muller, \& Bass, 1990). Thus, the diffusion of technological innovations came to be widely described by mathematical models, involving models of diffusion and contagion applicable to various phenomena and social structures (Bertotti, Brunner, \& Modanese, 2016). The BM has been widely used because the model is practical and straightforward to predict or to explain various diffusion phenomenon (Daim, Iskin, \& Ho, 2011).

The model considers the interaction between individuals, as well as marketing strategies, and it describes an S-shaped curve for the diffusion of products or practices. The BM is described by a series of non-linear differential equations of first order, as observed in the Equation (1). It proposes that diffusion occurs through two independents forces: (i) advertising (by innovators) and (ii) word of mouth (by imitators) (Bass, 1969): 


$$
\frac{d N(t)}{d t}=p[m-N(t)]+\frac{q}{m} N(t)[m-N(t)], \quad t \geq 0
$$

where $N(t)$ is the cumulative number of adopters in a potential market of size $m, p$ represents the innovative factor (independent of the number of adopters), and $q$ represents the imitation factor (dependent on the number of adopters). Besides the imitator and innovator mechanisms, the diffusion is based on a pre-determined potential market. In this model, as the fraction of adopters grows, the factor of adoption by word of mouth gains strength, inducing positive feedback (Bass, 1969). Therefore, the advertising factor, related to the innovative profile, loses its force on the rate of adoption.

\subsection{Model DEVELOPMENT AND ASSUMPTIONS}

Many authors have shown that an organization's adoption of ISO 9001 predicts the ISO 14001 behavior as well (Baek, 2017; Darnall, 2006; Delmas \& Montes-Sancho, 2011). In addition, lessons from the operation any of these management systems can also be reproduced in other standard (Stevens, Batty, Longhurst, \& Drew, 2012). Two factors stand out for the dissemination of ISO 50001 in eight of the twelve countries with the highest number of certifications, namely the use of renewable energy sources and the previous adoption of the standards. ISO 90001 and ISO 14001 (Lira, et al., 2019). That is, the trend in countries with low ISO 50001 certifications, as in the case of Brazil, is that the growth of this standard is driven by the adoption of older standards (as ISO 9001 and ISO 14001), in the timeline observed by the researchers. From this rationale, we assume that ISO 50001 will potentially follow a similar trend as ISO 9001 through time. Moreover, ISO 14001 has fewer historical data, thus, we focused on finding diffusion parameters from the QMS increase and use them for the EnMS diffusion.

Traditionally, businesses are classified in four size-segment groups: (i) micro-enterprises: up to 4 employees; (ii) small businesses: from 5 to 49 employees; (iii) medium-sized enterprises: from 50 to 249 employees and (iv) large companies: 250 or more employees (IBGE, 2018). However, in this study, micro-enterprises were not considered due to their unique characteristics, such as the provision of fewer resources (whether financial or operational), lack of formal planning, difficulty in attracting investment, susceptibility to a local economy solely, among others (Battisti $\&$ Perry, 2011). Moreover, from the different segments, we chose to use the industrial sector, which is the sector that has mostly pursued the standard (ABESCO, 2018).

From Equation (1) there are three parameters needed for the diffusion forecast: potential market $(m)$, innovator factor $(p)$ and imitator factor $(q)$. Two extensions to BM were considered: (i) dropout and (ii) an influential force named market relation factor $(m r)$. The first one relates to when the companies choose not to renew the management system, returning to potential adopters once again. The second one, while the diffusion of products is, in general, stimulated by advertising and imitation, in this study, we propose another influential force for the dissemination of ISO certification. This force is related to the behavior at which companies are influenced to conduct a direct manner, e.g., companies that require their suppliers to be also certified by a management system to maintain (or start) their partnership. We consider that its impact on the total adoption rate is calculated similarly to the imitator force (dependent on the cumulative adopters), but instead, proportional to a market relation factor $(m r)$ and not the imitator factor $(q)$.

Figure 1 presents the System Dynamics (SD) model developed for the diffusion of industries certified by ISO. This model is used for both the estimate of parameters through ISO 9001 historic match and for the diffusion of ISO 50001 in the long-term (2016-2040 timeframe). 


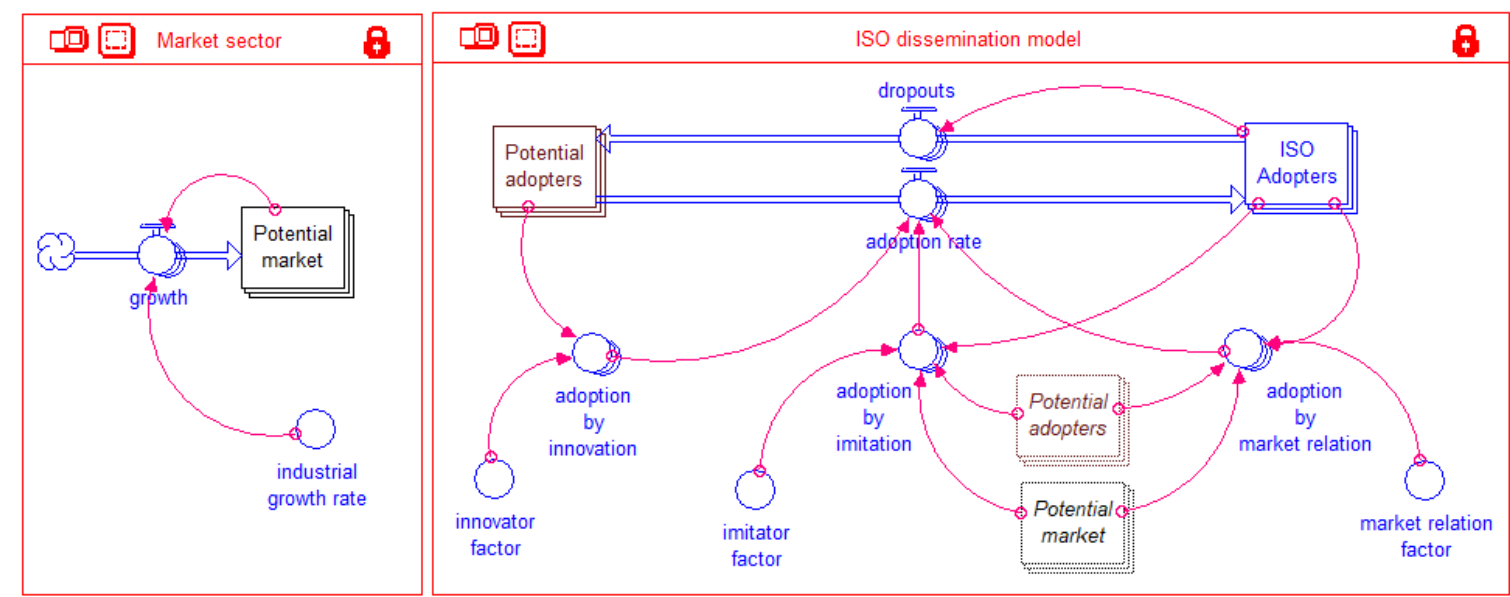

Figure 1. System dynamics model of management system certification diffusion based on the Bass diffusion theory divided into two sectors: (i) market and (ii) ISO dissemination model.

Source: Elaborated by the authors, 2018.

The use of an 'array' function over the model stocks (potential market, potential adopters, and ISO adopters), allows a deeper investigation of different companies' sizes. It allows the examining of each segment size response to the ISO certification expansion and the policies inducing its dissemination.

Equation (2) summarizes the variables involved in the account of the stock 'ISO adopters', the number of certified industries. The first three variables are summed in the 'adoption rate' flow variable in Figure 1.

$$
\begin{aligned}
& \text { ISO Adopters }=\begin{array}{l}
\text { Adoption from } \\
\text { advertising }
\end{array}+\begin{array}{l}
\text { Adoption from } \\
\text { word of mouth }
\end{array}+\begin{array}{l}
\text { Adoption from } \\
\text { market relation }
\end{array}-\text { dropout } \\
& \frac{d N(t)}{d t}=p[m-N(t)]+\frac{q}{m} N(t)[m-N(t)]+\frac{m r}{m} N(t)[m-N(t)]-0.05 N(t)
\end{aligned}
$$

Equation (3) includes the market relation force and dropout rate. We make some assumptions on how they respond to these different forces. First, the adoption by innovation would only be compatible with large enterprises, as the adoption of management systems is strongly linked to some factors, such as, e.g., employee availability, training, and available capital (Baek, 2017; Darnall, 2006).

On the other hand, adoption by imitation would be compatible with both large and medium industries, but not with the small-enterprises, because of their unique characteristics (Battisti \& Perry, 2011; Oliveira \& Serra, 2010). Industries with the provision of fewer resources (whether financial or operational) are more likely to lack formal planning, to have difficulty in attracting investment, and of being more susceptible to a local economy solely. Thus, they are more unlikely to merely copy management standards or practices based on success from other companies.

In terms of market relations, the closer the suppliers are to the focal company, the greater their reactive performance in environmental issues, while lower-tier suppliers generally tend 
BBR

17

586

to address environmental issues passively (Villena \& Gioia, 2018). However, all the industries can be influenced by this relation. Finally, we assume that the adoption by the market relation influence all companies, regardless of their size, since their relations in supply chain cover all size of enterprises (Baek, 2017; Darnall, 2006; Graafland, 2018; Sarkis et al., 2010). Chart 1 briefly summarizes which force type influence each organizational size, considered for the SD model and Table 1 presents the initial exogenous parameters.

Chart 1

Adoption types and their influence on the different market segments size

\begin{tabular}{|c|c|c|c|}
\hline Adoption type & Small business & Medium-sized & Large \\
\hline Innovation & & & $\checkmark$ \\
\hline Imitation & & $\checkmark$ & $\checkmark$ \\
\hline Market Relation & $\checkmark$ & $\checkmark$ & $\checkmark$ \\
\hline
\end{tabular}

Source: Elaborated by the authors, 2018.

Table 1

Initial setting values for the calibration of Bass coefficients factors

\begin{tabular}{lc}
\hline Model parameters & Value \\
\hline$m_{\text {total }}($ fixed value $)$ & $30000^{1}$ \\
$m_{\text {small }}$ & 6915 \\
$m_{\text {medium }}$ & 18926 \\
$m_{\text {large }}($ initial in 1997) & 4159 \\
$N(t)_{\text {total }}$ & 2068 \\
$N(t)_{\text {small }}$ & 103 \\
$N(t)_{\text {medium }}$ & 414 \\
$N(t)_{\text {large }}$ & 1551 \\
Dropout & $5 \%$ \\
\hline
\end{tabular}

${ }^{1}$ An increasing rate is considered in some scenarios, described in the next subsection.

Source: Elaborated by the authors, 2018.

The potential market $m_{\text {total }}$, in our case, is a rounded number of the maximum number of organizations certified by ISO 90001 achieved in the past 25 years (which was 28325 in 2011). The potential market of each segment size assumed that $100 \%$ of medium-size and large companies would be a potential market to be certified by ISO 9001. Thus, values for $m_{\text {medium }}$ and $m_{\text {large }}$ represent $100 \%$ of their market in 2016 (IBGE, 2018). Hence, the remaining numbers for the sum of 30000 industries (6915) were assigned for small businesses.

The initial number of adopters, $N_{\text {total }}$, is a known number. However, some assumptions were made for the initial numbers for each segment size. Different weight was attributed, that is: $75 \%$, $20 \%$ and $5 \%$ of the initial $N_{\text {total }}$ for large, medium and small industries, respectively (Table 1). The dropout rate is the average rate when considering all years since 1993. This dropout exists because market economic uncertainties, such as financial crises, may directly distort the attitude 
of companies towards environmentally friendly actions. Also, there may be changes in managerial or market strategies, making it unattractive to allocate resources for management systems.

Finally, having established every initial setting, we estimate the three factors $(p, q$ and $m r)$ using the optimization feature in Stella ${ }^{\oplus}$ Software from Isee Systems. The calibration metric chosen was the sum of squares error (SSE) between the total historical number of certified industries with ISO 9001 and the model's output, for 1997-2016 period. Figure 2 presents the simulation fit result, and Table 2 presents the fitted values obtained through the calibration.

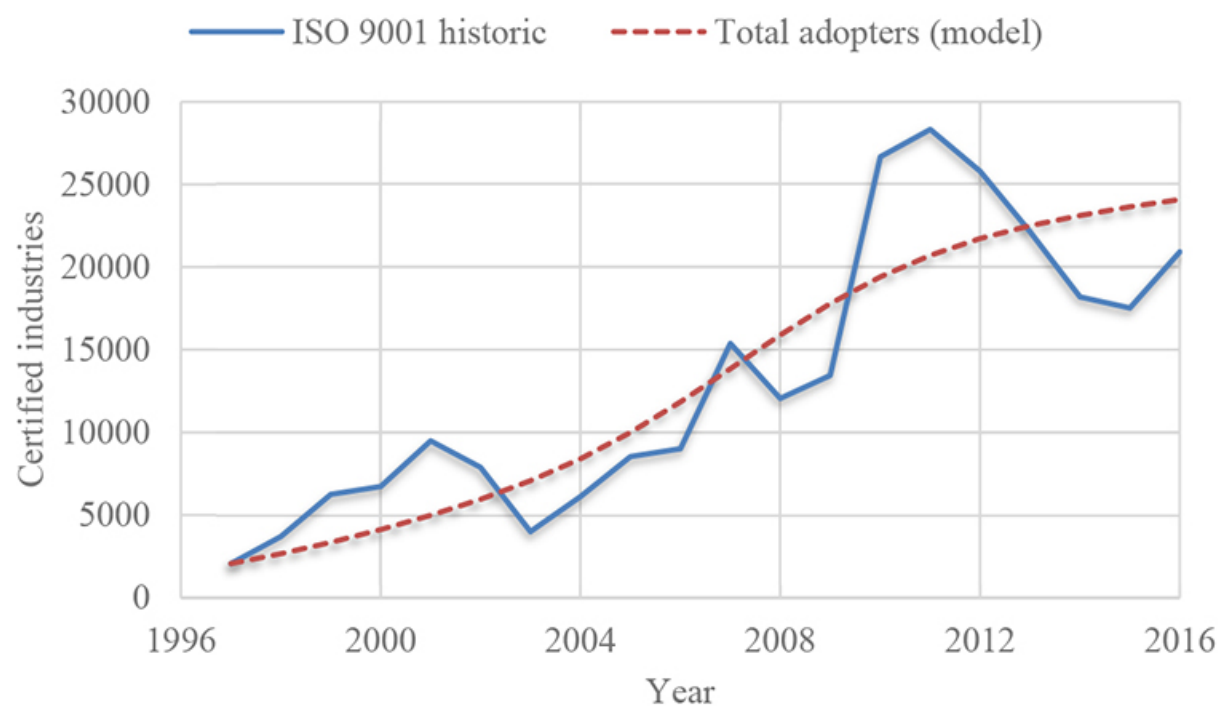

Figure 2. Historical numbers of industries certified with ISO 9001 (blue) and simulated results (red) using estimated parameters shown in Table 2.

Source: Elaborated by the authors, 2018.

Table 2

Bass diffusion model coefficients $p$ and $q$ as well as the proposed coefficient mr adjusted for the ISO 9001 historic match. These rates are then used for the ISO 50001 simulation

\begin{tabular}{ccc}
\hline Model coefficients & Calibration range values & Result value \\
\hline$p$ & $0.001-0.01$ & 0.001 \\
$q$ & $0.1-0.3$ & 0.188 \\
$m r$ & $0.3-0.5$ & 0.3 \\
\hline
\end{tabular}

Source: Based on IBGE, 2018, elaborated by the authors, 2018.

Note that the range values for $q$ and $m r$ are different. At first, since they are calculated by the same rationale behind them, they should be equally tested. However, due to our assumption that all industry sizes are influenced by market relation, we restrain them to assume higher and lower value for market relation and imitator rates, respectively.

Some similar results comparisons of these value can be seen in Q. Zhu, Tian, and Sarkis (2012). The authors used BM to analyze the ISO 14001 certification and eco-labeling practices in China and found $p$ values varying between 0.0003 and 0.002 , and $q$ values between 0.4 and 0.7 (different potential market scenarios were involved). Another comparison is found in Sultan, Farley, and Lehmann (1990), with an average of 0.03 for the coefficient of innovation and 0.38 for the coefficient of imitation, when investigating general innovation diffusion. 


\subsection{DEFINING SCENARIOS}

Given the timid initial uptake of ISO 50001 certification in Brazil (ISO, 2017), we examine the influence that more coercive forces may have on its adoption. Moreover, we investigate how these additional stakeholder pressures, through government policies and incentives, could make an impact on different industries size. Several countries have been under different policies that seem to have a positive outcome regarding the number of enterprises certified by the standard (McKane et al., 2017). Thus, the scenarios assessed would affect different industrial sizes, with the inference that national programs would take place. Chart 2 presents each scenario along with its descriptions and implications in the model.

Chart 2

Scenarios descriptions and implications

\begin{tabular}{|c|c|}
\hline Scenarios & Descriptions and implications \\
\hline Reference Mode & $\begin{array}{l}\text { This is the scenario where the problem is characterized (Sterman, 2000), i.e., if nothing } \\
\text { is done, in what way will the standard develop over time in each industrial segment size. }\end{array}$ \\
\hline $\begin{array}{l}\text { Scenario } 1 \text { - } \\
\text { Moderate } \\
\text { coercive } \\
\text { pressure }\end{array}$ & $\begin{array}{l}\text { When programs such as "training for energy managers" (TREM) are developed in the } \\
\text { country from } 2020 \text { onwards. With this, the imitator force in small industries is activated, } \\
\text { assuming the same factor value as medium and large enterprises. By this, we assume that } \\
\text { the potential market for the small-businesses would increase, assuming the average 3\% } \\
\text { industrial growth increase per year (IBGE, 2018). }\end{array}$ \\
\hline $\begin{array}{l}\text { Scenario } 2- \\
\text { High } \\
\text { coercive } \\
\text { pressure }\end{array}$ & $\begin{array}{l}\text { When programs such as "financial assistance for energy efficiency and EnMS } \\
\text { implementation" (FEEM) and "tax policies incentives" (TP) take place from } 2020 \text { onwards. } \\
\text { With this, the innovator force in both small and medium-size industries are activated } \\
\text { (Chart 1), assuming the same innovator rate as large companies. By this, we assume that } \\
\text { the potential market for both small and medium-businesses would increase, assuming the } \\
3 \% \text { industrial growth rate per year. }\end{array}$ \\
\hline $\begin{array}{l}\text { Scenario 3- } \\
\text { Aggressive } \\
\text { coercive } \\
\text { pressure }\end{array}$ & $\begin{array}{l}\text { The case when ISO } 50001 \text { becomes mandatory for all large industries from } 2030 \text { onwards. } \\
\text { As industries would be previously acknowledged of such policy, from } 2025-2029 \text {, " } q \text { " and } \\
\text { " } m r \text { " increase in } 50 \% \text {, as both imitator and market relation forces would intensify over this } \\
\text { segment. By this, we include a potential market increase for large companies, assuming the } \\
\text { average } 3 \% \text { industrial growth rate per year. }\end{array}$ \\
\hline Scenario 4 & Previous policies altogether, along with its implications. \\
\hline Scenario 5 & $\begin{array}{l}\text { Previous policies altogether, but here the total potential market is fixed, assuming the same } \\
\text { value as the ISO } 9001 \text { potential market, i.e., } 30 \text { thousand. }\end{array}$ \\
\hline
\end{tabular}

Source: Elaborated by the authors, 2018.

The industrial growth rate considered in scenarios 1, 2 and 3 was based on historical data from the Brazilian Institute of Geography and Statistics (IBGE, 2018). We assume the average rate of 3\% per year for all company sizes as a model limitation. Implementing environmental initiatives such as EnMS requires both knowledge and personal capabilities. By the occurrence of programs such as TREM, scenario 1 assumes a setting where companies that most likely lack in staff availability would be induced to implement ISO 50001, as they would have opportunities of learning through training and not going after themselves. Knowing that environmental practices may be enhanced by frequent training programs (Phan \& Baird, 2015), induced by collaborative relationships (Darnall, Henriques, \& Sadorsky, 2008) and thus receive greater influence when negotiating regulation terms with the government (Sarkis et al., 2010), small companies would be willing to imitate their market peers and implement ISO 50001. 
In scenario 2, we assume that the existence of financial support should, somehow, induce small and medium-sized companies to invest in the ISO 50001 implementation. They would be more susceptible to innovate and try out this new energy management system. In scenario 3, a more aggressive coercive pressure is set, which arises from a mandatory measure that all large industries would need to implement the standard by 2030. This segment of industries is more likely to provide personal to fully work on its implementation and monitoring, as well as more likely to consume more energy.

Finally, in both scenario 4 and 5, it was assumed that all policies are implemented and the main difference is at the total potential market size. While we assume that the potential market might annually increase due to the incentives proposed by the government, in our last scenario (scenario 5), this value remains constant at the number of industries certified by ISO 9001 at present. The time horizon chosen to simulate is the 2016-2040 periods, which is the average period in which ISO 9001 has been on the market (25 years, since 1993).

\section{RESULTS AND DISCUSSIONS}

\subsection{SENSITIVITY ANALYSIS}

Due to the uncertainties regarding the parameters estimated, we performed a sensitivity analysis of three variables: (a) innovative - $p$; (b) imitator - $q$; and (c) market relation - $m r$ factors. In this analysis, we considered two variations from the reference mode: (1) fixed potential market; (2) variable potential market, or a potential market increase.

Since the innovator factor is directly related to the potential market, it is expected to have a more significant influence on the number of adopters at the beginning of the period under analyses. On the other hand, the imitation and market relation factors present a large contribution in the total number of adopters over time, because both are related not only to the potential market but also to the total number of adopters (similar dynamics).

Figure 3 presents the simulations of the two model variations ( 1 and 2 ), based on the considerations in Table 1, with the response of companies adopting ISO 50001 certification when different values of the factors $p, q$, and $m r$ are assumed. These factors were tested considering an interval between them, in both model variations.

Considering the sensitivity analysis of the reference mode in $\mathrm{a} 1, \mathrm{~b} 1$ and $\mathrm{c} 1$, independent of the values assumed, the adoption (certified companies) does not reach the initial potential market, i.e., 30 thousand. This can be partially explained by the occurrence of the dropout considered in the model. Thus, even without an increase of potential market in the same period, we would not have the full potential market certified by ISO 50001 by 2040 .

It is noticeable that when considering a variation in the potential market, the results of certified companies are more expressive, surpassing the initial market of 30 thousand for some values of $q$ and $m r$. This difference is significant: for an imitation factor of 0.7 , there are approximately 25 thousand certified companies considering a fixed potential market (b1), against nearly 40 thousand certified companies when considering variable potential market (b2) by 2040. The same is true for the case of $m r=0.7$ : an adoption of almost 30 thousand companies when the market is fixed (c1) and nearly 50 thousand certified companies when there is a growing market (c2).

As for the innovator factor ( 1 and a2), in more distant time, the change in its value does not alter the number of adopters significantly. This force influences only large companies (reference mode scenario). By 2040, an increase of this factor $(0.0001-0.1)$, provides a difference of 98 and 350 certified industries from reference mode in a1 and a2, respectively. This shows how 
17

590

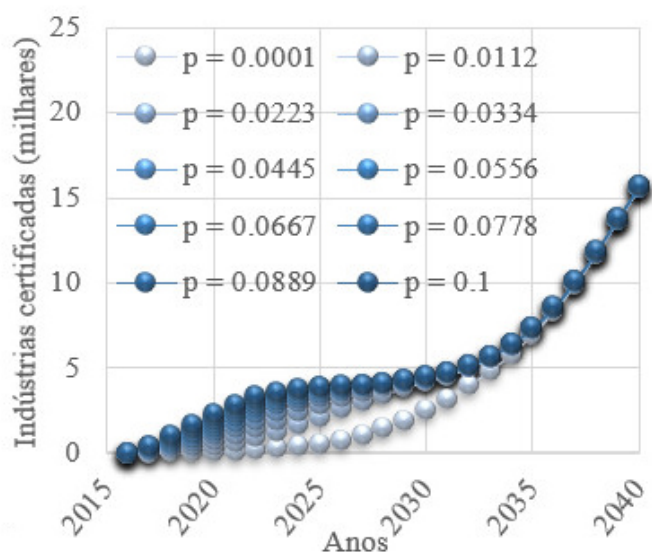

(a1)

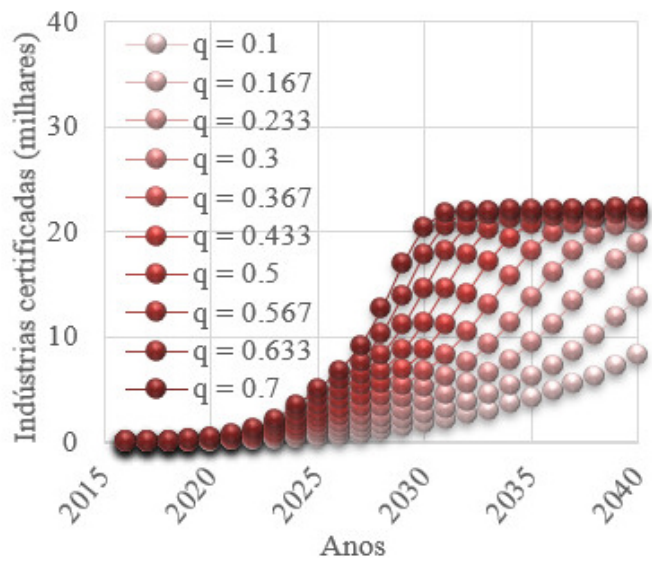

(b1)

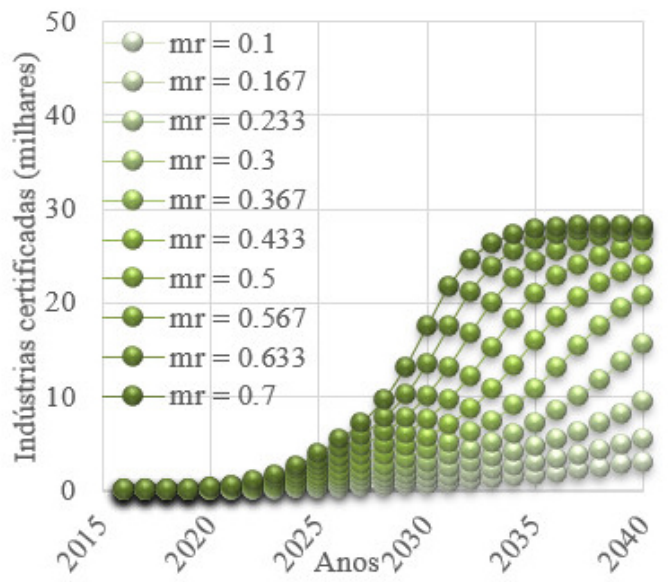

(c1)

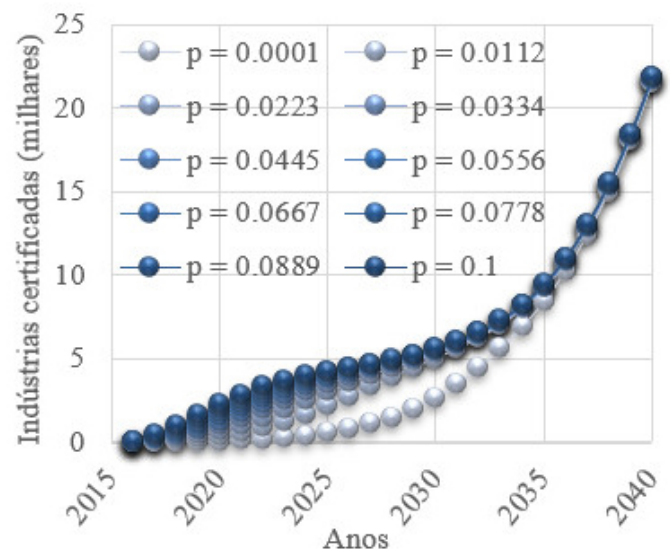

(a2)

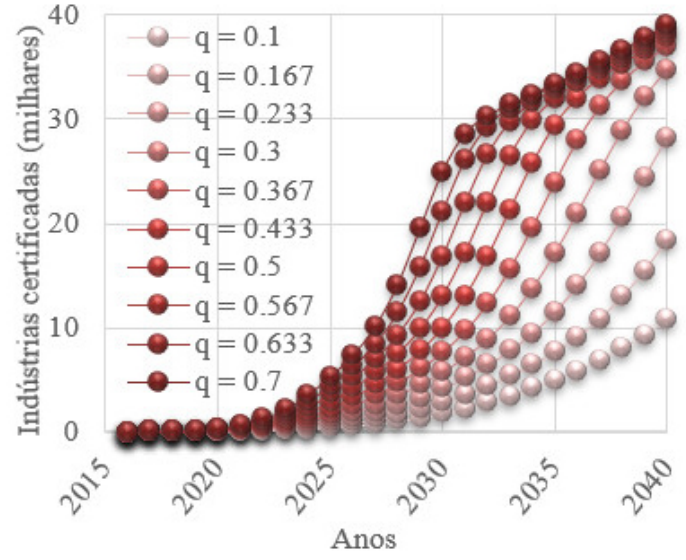

(b2)

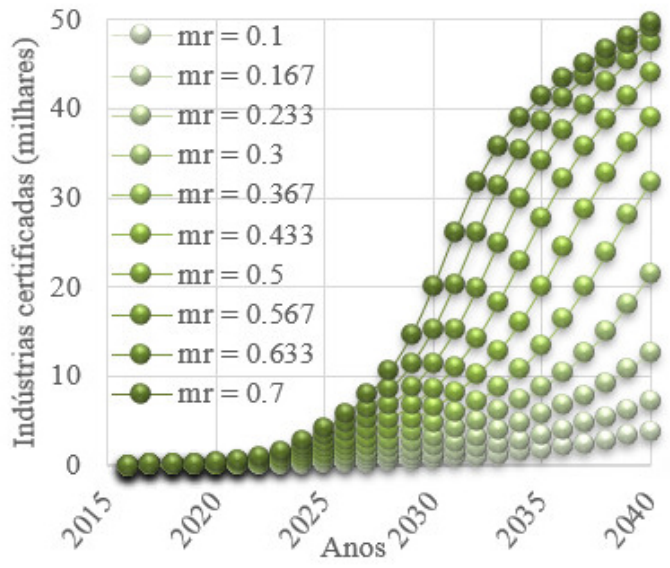

(c2)

Figure 3. Sensitivity analysis of the estimated parameters: innovator (a), imitator (b) and market relation (c) factors, from the reference mode setting with fixed and increasing total potential market in number 1 and 2 , respectively. Source: Elaborated by the authors, 2018. 
the innovator force has little relevance in a long-term perspective, as predicted in the model. However, this assertion is not true when we observe periods closer to the certification launch.

On the other hand, the imitator factor (b1 and b2) has considerable sensitivity to the total number of adopters. This result is related to the identification of the imitator profile of both medium and large companies. The contagion of medium and large companies certified with the non-certified ones will increase more and more over time. Thus, changes in the value of the factor $q$ imply in significant changes in the total number of adopters. By 2040, considering an increase of $q$ factor $(0.1-0.7)$, there is a delta of approximately 15 and 28 thousand certified companies in b1 and b2, respectively.

As for the market relation force, in both cases (c1 and c2) the $m r$ factor presents the most sensitivity response to the number of ISO 50001 adopters. This profile was expected since it reflects the way companies of all sizes are induced by the market. Small, medium, and large companies are influenced by the market relation and therefore are most influenced by it. The various values tested show that a little variation implies in a rapid increase in adoption over time. By increasing the $m r$, there is an increase of approximately 25 and 45 thousand certified enterprises in $\mathrm{c} 1$ and $\mathrm{c} 2$, respectively.

\subsection{SCENARIOS RESULTS}

Figure 4 presents the potential number of industries certified with ISO 50001 by each size segment and in the total number of adopters per scenario. As expected, the reference mode provided the lowest result through time, with little over 15 thousand industries by 2040 . With similar expectance tendency, the highest result did come from scenario 4, when all policies took place, with over 40 thousand certifications. For better visualization, the time horizon chosen for size-segment results were from 2025 onwards. Table 3 provides the percentage difference between each result from the reference mode in 2040.

Our main goal was not to forecast a specific number of how many industries would be certified by ISO 50001 in Brazil. Although system dynamics modeling does allow this outcome, the main result is an interpretation and understanding of the dynamics involving a certain process/ problem to assist policies formulation (Ciarli, Coad, \& Rafols, 2016). We focused on comparing the potential increase the policies and incentives can bring to the reality of the standard diffusion in percentage terms. In addition to this, its market proportion achieved is also discussed.

The coercive pressure is the most obvious when it comes to environmental issues (Zhu \& Sarkis, 2007) and can be comprehended as the main reason why organizations implement proactive green strategies. This finding goes in line with Pham (2015), who studied the influence of institutional theory in the coverage of EMSs. Among other results, the author confirmed a positive correlation between coercive pressures to the scope of Environmental Management Systems (EMS), stating that both the adoption of SGAs and their coverage can be significantly affected by government, in this way the government can create regulatory pressures to induce improvements in environmental performance (Pham, 2015) and this also applies to issues related to energy management and emissions.

When addressing environmental issues at the supply chain level, there can be passive, reactive, or proactive responses; however, lower-level suppliers tend to respond more passively to environmental issues (Villena \& Gioia, 2018). Thus, for these suppliers, national polices and pressures exert more influence on their attitude towards environmental issues than market relations. According to the International Energy Agency (IEA), public policies are essential to improve the EE (IEA, 
BBR

17

592

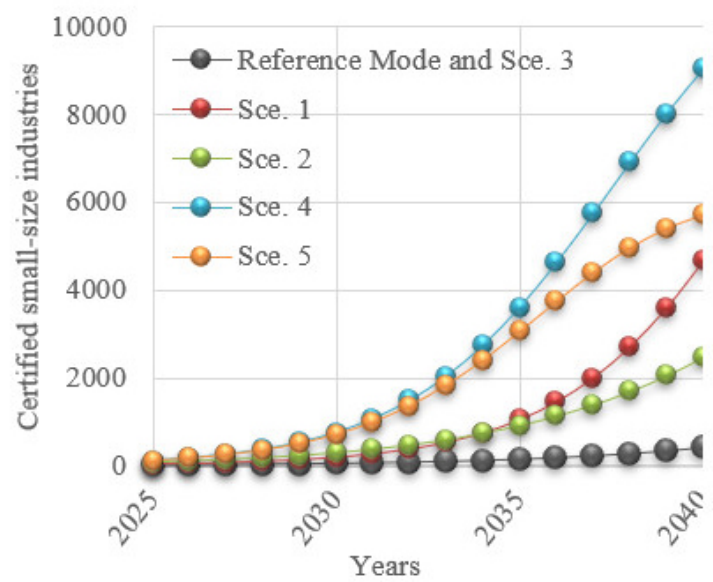

(a)

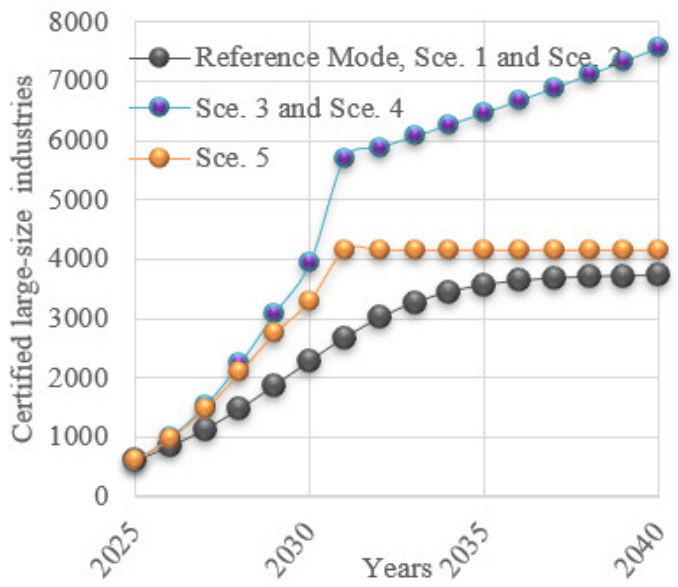

(c)

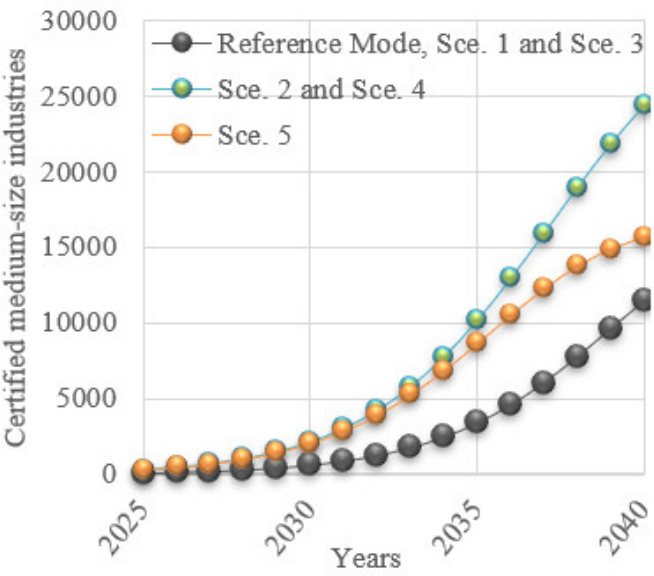

(b)

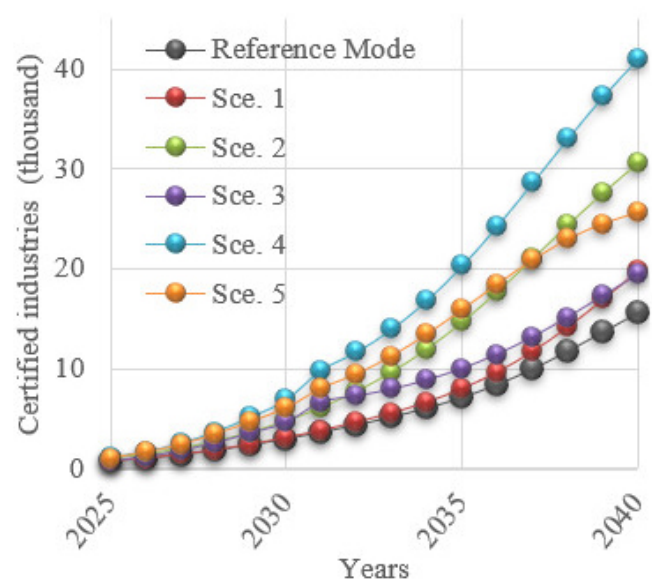

(d)

Figure 4. Simulated results of industries certified with ISO 50001 in (a) small businesses, (b) medium-size (c) large and (d) total number of industries in each scenario through time.

Source: Elaborated by the authors, 2018.

Table 3

Percentage increase from the Reference Mode scenario respective to industry size and in total size results

\begin{tabular}{lccccc}
\hline Scenario & 1 & 2 & 3 & 4 & 5 \\
\hline Small (\%) & 1068 & 520 & 0 & 2161 & 1326 \\
Medium (\%) & 0 & 113 & 0 & 113 & 37 \\
Large (\%) & 0 & 0 & 103 & 103 & 12 \\
Total (\%) & 27 & 97 & 25 & 163 & 64 \\
\hline
\end{tabular}

Source: Elaborated by the authors, 2018. 
2013). In the case of this study, we separated into a moderate, a higher, and aggressive coercive pressure, as different scenarios.

If moderate coercive pressure, such as national policy in support of industrial energy management training takes place (scenario 1), smaller companies could achieve a 1068\% increase in its certification uptake (over 4 thousand certifications against around 400 in reference more, Figure 4a). The assumption involves the imitator force influencing the industry decision to obtain the certification if only, first, immersed in a training culture from stakeholders. Some abroad examples are the Federal Energy Management Program Training promoted by the Office of Energy Efficiency \& Renewable Energy (Energy, 2018) in the US or from a professional body for the energy industry from Energy Institute in the UK (Energy Institute, 2018). This scenario does not alter medium and large companies' results, with zero increase from reference mode, as they are more likely to have staff designated to search out on energy efficiency concerns and, thus, their imitator reality already in place.

When higher coercive pressure, such as financial and tax incentives enter in the scene (scenario 2), both small and medium-sized enterprises have their dissemination increased by $520 \%$ and $113 \%$, respectively, due to the innovator dimension. Although a positive outcome was obtained for small business, the results show approximately half of the number achieved in scenario 1 . This is due to the assumptions that financial assistance and tax policy incentives would interfere in the innovator force only, which express itself less intensely than other forces (Figure 3). The idea is that, with financial incentives, they would be willing to put on their agenda the implementation of ISO 50001 by their own initiative.

Large companies, on the other hand, do not present an increased rate compared with reference mode in scenario 2 . This is not to affirm that financial support does not come conveniently for them, it is simply due to the assumption that this policy occurrence would not alter its dynamic. Their adoption driving forces are already in operation and, thus, the potential market that was assumed for them (100\% of their market in 2016) should not be influenced significantly.

In scenario 3, large businesses increase by $103 \%$ in their number of certifications by 2040 . This is the case of the aggressive coercive pressure, assuming the government would set a mandatory policy over this segment. In the case where all studied policies are combined, scenario 4 , a significantly higher increase number is achieved by small-sized businesses compared with the other segment sizes. In fact, by policies integration, a higher certification number of small companies with ISO 50001 is achieved when compared with the numbers reached when policies are assessed individually and then summed (9050 against 6756 certified small enterprises). This occurs due to the cooperation of both innovation and imitation adoption pattern that are set simultaneously providing synergic results.

The results reflect on the importance of policies and incentives toenterprises of all sizes, and in this case, to expand its impact on small-size industries, known for their shorter uptake in management system such as ISO. Graafland (2018) confirmed that substantial positive impacts are achieved in small and medium-sized enterprises only when they are connected to a network of companies. Still, a double increase result in both medium and large companies should not be disregarded. They both start with a higher potential market and driving adoption forces (Table 1) and have the highest weight on the responsibility of energy use.

Finally, scenario 5 presents results in which all policies are considered but with a constant potential market. Thus, in Figure 4, its results show an S-shape (except in the case of Figure 4c) behavior until 2040, representing a near end of its diffusion. Nevertheless, if this analysis approach is considered, a total of 25 thousand industries would be certified by 2040 (4d), nearly 5 thousand 
BBR

17

594

behind its total potential market and after approximately 30 years of diffusion (2011-2040). Figure 5 presents the proportion market achieved by ISO 50001 certification in each segment size and total results in each scenario. If stakeholders' coercive pressures persist low in boosting energy management strategies, the potential adopters achieved is approximately half from the potential market (reference mode) by 2040 . This points out to the urgency of additional national policies and incentives.

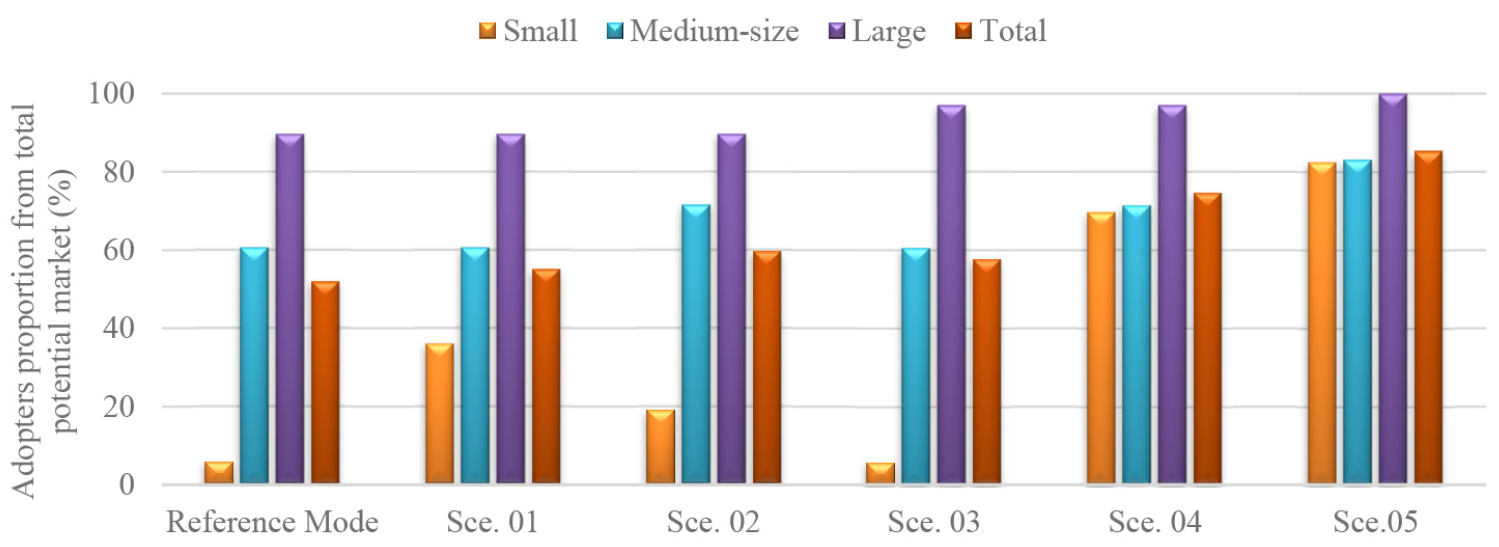

Figure 5. Potential market certified by ISO 50001 at the end of the simulation period, 2040.

Source: Elaborated by the authors, 2018.

Simulation results indicate that, by 2040, most of the large size industries market will implement the certification, with a standout average of $94 \%$, when considering all scenarios assessed. The least one is identified by small businesses, with an average of $36 \%$ and medium-sized companies with $68 \%$. Regarding the total number of industries, this value is $64 \%$.

One relevant highlight from Figure 5 is the importance which further coercive pressure have in raising small businesses in attaining the certifications. Only when strategies fostering trainings and tax incentives occur would this segment surpass a 50\% chance of achieving its market. On the other hand, the aggressive coercive pressure tested in this study turns out to be not so relevant, as large companies are more likely and have more capacities to endorse this certification. Even with no policies, results show a 90\% market achievement for large industries by 2040 . Thus, even though the implication behind the policy is aggressive, at the end it does not express itself accordingly.

If we go beyond our consideration of coercive pressures in different market sizes, a case in China has shown that government initiatives considering companies according to their intensity of energy use reflect improvements in energy consumption. In 2006, China launched the program Top-1000 aiming at the 1000 companies of the country's largest energy consumption (which accounted for almost half of the industrial energy consumption and about one-third of the total energy of China) (Price, Wang, \& Yun, 2010). The following year, the country also reviewed the Law of Conservation of Energy. Both initiatives were aimed at improving energy efficiency, achieving a reduction of energy per unit of GDP of approximately $19 \%$ between the years of 2006 and 2010 (Ke et al., 2012). The energy efficiency goals were incorporated into their performance evaluations by managers of companies and resulted in a successful impact 
higher than expected from the program. Its expansion forced more than 16,000 companies to achieve the goal of saving energy (IEA, 2015).

The energy saving numbers led China to a leadership position in the International Energy Agency countries, while at the same time they showed an energy reduction of about $14 \%$. In this context, we can affirm the relevant role the government has on organizations to adopt green strategies. The ISO 50001 certification is one key strategy for industries and thus it should be further encouraged through national programs to bring management changes and generate meaningful results over time.

\section{CONCLUSIONS}

Through a system dynamics model based on the Bass diffusion theory, stakeholder pressures were investigated in their influence in the diffusion of EnMS - ISO 50001 certification over different sizes enterprises. An extension to Bass model was proposed, regarding the driving forces of diffusion, i.e., besides adoption by innovator and imitator, an adoption by market relation was considered. With this, the characteristics of each industry size type in their adoption process pattern could be assessed individually.

With the assumption that small-size industries are unless there are incentives, induced to acquire the certification only through market relation, this segment was most influenced by stakeholder pressures tested. National programs that induced them into imitating their peers, such as training for energy management, accelerated their involvement with the subject. Moreover, policies that create financial assistance can also bring considerable outcome. Other policies could be tested and considered, but the highlight is that by shortening the gap between complete uninterested (or inability) and total awareness is a way to overcome low numbers and their little perspectives.

On the other hand, large industries perspectives are more prominent to adopt even with the lack of further coercive pressure. They have more staff and resources capability and are influenced by all driving adoption forces. Policies and incentives can stimulate their uptake, such as the aggressive policy tested, in which they would be obligated to obtain ISO 50001 certification from 2030 onwards. However, even if this aggressive mandatory policy takes place, the result is not substantial as one would think. By 2040, this segment would undoubtedly be $100 \%$ of its market, but without it they would still reach a high number of over $90 \%$. What does happen is that it reaches its full market faster, but perhaps it would not be necessary to propose a policy so stringent as this one, other types of incentives could satisfy.

Integrated policies seem to be the way to fully influence industry of all sizes and provide synergic results. One certainty remains that more national programs should be further encouraged if the country wants to help industries develop more efficiently. Even though the aggressive policy tested in large companies is not particularly supported, further studies could search for other strategies to accelerate their involvement with energy management, as they potentially represent a higher weight of energy use in their production.

Another approach for further research would be to verify if indeed market relation forces have a greater influence on the EnMS certification adoption from companies' viewpoint. We suggest that a survey research approach could be done for this end, with different companies involved in the supply chain. Through the same survey, the other driven forces could also be verified as well as the gathering of incisive results regarding the strength that different policies could have in their decision to adopt ISO 50001. 
BBR

17

596

One limitation of this study regards the initial adoption numbers for each industry size. Although the total number, used in the ISO 9001 historic match and the ISO 50001 diffusion investigation, is a known number, its initial proportion per segment size was based on assumption. Even though the proportion adopted is believed to be reasonable, and the main goal was not the forecasting number of certified industries, this limitation could reflect on the results if accuracy is intended.

Furthermore, changes in the driving forces of $p, q$ and $m r$ factors over time have not been considered. Incentives and policies could somewhat end up increasing their rate, which would hasten their uptake (or vice-and-versa). Only in scenario 3 that these factors were increased for adequacy purpose from larger companies' part. However, besides this, the rates remained the same and attention was brought to activating different adoption forces according to the policies involved.

This investigation allows policymakers to consider different types of national policies and incentives for the ISO 50001 dissemination. It can provide implications for both industry and governments, and ultimately, understand how different strategies and programs pressures can affect different size industries and enhance energy efficiency development. This understanding can foster the diffusion of ISO 50001 allowing a significant reflection on global GHG emissions, helping to combat climate change. Since there are no support programs to ISO 50001 in Brazil, this research can contribute to future decision-making by indicating how different actions can impact the EnMS adoption. Finally, it aids in suggesting pathways to energy efficiency improvements and carbon footprint reductions from industries, as the government has already shown interest in the principles of ISO 50001, pointing it as one of the key actions for energy efficiency in the industry. The results go beyond reducing GHG emissions, reflexing in reduced company operating costs, energy consumption, and productivity gains, generating greater business competitiveness.

\section{REFERENCES}

ABESCO. (2018). ISO 50001 - Gestão de Energia. Retrieved 14 apr, 2018, from http://www.abesco. com.br/pt/iso-50001-gestao-de-energia/

Baek, Kyungmin. (2017). The Diffusion of Voluntary Environmental Programs: The Case of ISO 14001 in Korea, 1996-2011. Journal of Business Ethics, 145(2), 325-336. http://dx.doi.org/10.1007/ s10551-015-2846-3

Ball, A., \& Craig, R. (2010). Using neo-institutionalism to advance social and environmental accounting. Critical Perspectives on Accounting, 21(4), 283-293. doi: 10.1016/j.cpa.2009.11.006

Bass, Frank M. (1969). A New Product Growth for Model Consumer Durables. Management Science, 15(5), 215-227. doi: http://dx.doi.org/10.1287/mnsc.15.5.215

Battisti, Martina, \& Perry, Martin. (2011). Walking the talk? Environmental responsibility from the perspective of small-business owners. Corporate Social Responsibility and Environmental Management, 18(3), 172-185. doi: http://dx.doi.org/10.1002/csr.266

Bertotti, M. L., Brunner, J., \& Modanese, G. (2016). Innovation diffusion equations on correlated scale-free networks. Physics Letters A, 380(33), 2475-2479. http://dx.doi.org/10.1016/j. physleta.2016.06.003

Brasil. (2019). Plano Decenal de Expansão de Energia 2029. Retrieved 12 dec, 2019, from Ministério de Minas e Energia: Empresa de Pesquisa Energética http://www.epe.gov.br/sites-pt/publicacoesdados-abertos/publicacoes/PublicacoesArquivos/publicacao-422/PDE\%202029.pdf 
Campos, Lucila M. S. (2012). Environmental management systems (EMS) for small companies: a study in Southern Brazil. Journal of Cleaner Production, 32, 141-148. https://doi.org/10.1016/j. jclepro.2012.03.029

Ciarli, Tommaso, Coad, Alex, \& Rafols, Ismael. (2016). Quantitative analysis of technology futures: A review of techniques, uses and characteristics. Science and Public Policy, 43(5), 630-645. http:// dx.doi.org/10.1093/scipol/scv059

Daim, Tugrul U., Iskin, Ibrahim, \& Ho, Daniel. (2011). Technology forecasting for residential energy management devices. Foresight, 13(6), 70-87. http://dx.doi.org/10.1108/14636681111179609

Darnall, Nicole. (2006). Why firms mandate ISO 14001 certification. Business and Society, 45(3), 354-381. http://dx.doi.org/10.1177/0007650306289387

Darnall, Nicole, Henriques, Irene, \& Sadorsky, Perry. (2008). Do environmental management systems improve business performance in an international setting? Journal of International Management, 14(4), 364-376. https://doi.org/10.1016/j.intman.2007.09.006

Delmas, Magali A., \& Montes-Sancho, Maria J. (2011). An Institutional Perspective on the Diffusion of International Management System Standards: The Case of the Environmental Management Standard ISO 14001. Business Ethics Quarterly, 21(1), 103-132. http://dx.doi.org/10.1017/ S1052150X00010289

DiMaggio, Paul J., \& Powell, Walter W. (1983). The Iron Cage Revisited: Institutional Isomorphism and Collective Rationality in Organizational Fields. American Sociological Review, 48(2), 147-160. http://dx.doi.org/10.2307/2095101

Energy. (2018). Federal Energy Management Program Training. Retrieved 14 april, 2018, from https:/www.energy.gov/eere/femp/federal-energy-management-program-training

Energy Institute. (2018). Energy Institute. Retrieved 14 april, 2018, from https://www.energyinst. org/about-us

Graafland, Johan J. (2018). Ecological impacts of the ISO14001 certification of small and medium sized enterprises in Europe and the mediating role of networks. Journal of Cleaner Production, 174, 273-282. http://dx.doi.org/10.1016/j.jclepro.2017.10.322

Henriques, I., \& Sadorsky, P. (2013). Environmental management practices and performance in Canada. Canadian Public Policy, 39(Suppl. 2), S157-S175. http://dx.doi.org/10.3138/cpp.39. Supplement2.S157

IBGE - Instituto Brasileiro de Geografia e Estatística. (2018). Pesquisa Industrial Anual. Retrieved 14 feb 2018, from https:/www.ibge.gov.br/estatisticas-novoportal/economicas/industria/9042pesquisa-industrial-anual.html? \& $\mathrm{t}=\mathrm{download} s$

IEA - International Energy Agency. (2013). Tracking Clean Energy Progress 2013. Retrieved 17 APril 2018, from https://webstore.iea.org/tracking-clean-energy-progress-2013

IEA. (2015). Energy and Climate Change. World Energy Outlook Special Report, 1-200. http:// dx.doi.org/10.1038/479267b

ISO. (2011). ISO launches ISO 50001 energy management standard. Retrieved April 10 2018, from https://www.iso.org/news/2011/06/Ref1434.html

ISO. (2017). ISOSurveyof certifications to managementsystem standards-Full results. RetrievedApril 10, 2018 https://isotc.iso.org/livelink/livelink?func=1l\&objId=18808772\&objAction=browse\&viewType=1 
BBR

17

598

Jabbour, Ana Beatriz Lopes de Sousa, Verdério Júnior, Sílvio Aparecido, Jabbour, Charbel José Chiappetta, Leal Filho, Walter, Campos, Lucila S., \& De Castro, Rosani. (2017). Toward greener supply chains: is there a role for the new ISO 50001 approach to energy and carbon management? Energy Efficiency, 10(3), 777-785. http://dx.doi.org/10.1007/s12053-016-9478-z

Jovanović, Bojana, \& Filipović, Jovan. (2016). ISO 50001 standard-based energy management maturity model - Proposal and validation in industry. Journal of Cleaner Production, 112, 27442755. http://dx.doi.org/10.1016/j.jclepro.2015.10.023

Kanneganti, Harish, Gopalakrishnan, Bhaskaran, Crowe, Ed, Al-Shebeeb, Omar, Yelamanchi, Tarun, Nimbarte, Ashish, . . Abolhassani, Amir. (2017). Specification of energy assessment methodologies to satisfy ISO 50001 energy management standard. Sustainable Energy Technologies and Assessments, 23, 121-135. https://doi.org/10.1016/j.seta.2017.09.003

Ke, Jing, Price, Lynn, Ohshita, Stephanie, Fridley, David, Khanna, Nina Zheng, Zhou, Nan, \& Levine, Mark. (2012). China's industrial energy consumption trends and impacts of the Top-1000 Enterprises Energy-Saving Program and the Ten Key Energy-Saving Projects. Energy Policy, 50, 562-569. http://dx.doi.org/10.1016/j.enpol.2012.07.057

Kilbourne, W. E., Beckmann, S. C., \& Thelen, E. (2002). The role of the dominant social paradigm in environmental attitudes: a multinational examination. Journal of Business Research, 55(3), 193-204. https://doi.org/10.1016/S0148-2963(00)00141-7

Lira, Jean, Salgado, Eduardo, Beijo, Luiz. (2019). Which factors does the diffusion of ISO 50001 in different regions of the world is influenced?. Journal of Cleaner Production, 226, 759-767. https:// doi.org/10.1016/j.jclepro.2019.04.127

Mahajan, Vijay, Muller, Eitan, \& Bass, Frank M. (1990). New Product Diffusion Models in Marketing: A Review and Directions for Research. Journal of Marketing, 54(1), 1-1. http://dx.doi. org/10.2307/1252170

Masocha, R., \& Fatoki, O. (2018). The role of mimicry isomorphism in sustainable development operationalisation by SMEs in South Africa. Sustainability (Switzerland), 10(4). http://dx.doi. org/10.3390/su10041264

McKane, Aimee, Therkelsen, Peter, Scodel, Anna, Rao, Prakash, Aghajanzadeh, Arian, Hirzel, Simon, ... O'Sullivan, John. (2017). Predicting the quantifiable impacts of ISO 50001 on climate change mitigation. Energy Policy, 107, 278-288. http://dx.doi.org/https://doi.org/10.1016/j. enpol.2017.04.049

MMA - Ministério do Meio Ambiente do Brasil. (2016). Mundo firma pacto contra aquecimento global. Retrieved 17 April, 2018, from http://www.mma.gov.br/index.php/comunicacao/agenciainformma?view=blog\&id $=1548$

Nicole, Darnall, Irene, Henriques, \& Perry, Sadorsky. (2010). Adopting Proactive Environmental Strategy: The Influence of Stakeholders and Firm Size. Journal of Management Studies, 47(6), 1072-1094. http://dx.doi.org/10.1111/j.1467-6486.2009.00873.x

Oliveira, Otávio José de, \& Serra, José Roberto. (2010). Benefícios e dificuldades da gestão ambiental com base na ISO 14001 em empresas industriais de São Paulo. Production, 20(3), 429-438. http:// dx.doi.org/10.1590/S0103-65132010005000013

Pham, T. H. H. (2015). Energy management systems and market value: Is there a link? Economic Modelling, 46, 70-78. http://dx.doi.org/10.1016/j.econmod.2014.12.038 
Phan, Thanh Nguyet, \& Baird, Kevin. (2015). The comprehensiveness of environmental management systems: The influence of institutional pressures and the impact on environmental performance. Journal of Environmental Management, 160, 45-56. http://dx.doi.org/10.1016/j.jenvman.2015.06.006

Pombo, F. R., \& Magrini, A. (2008). An overview of the application of ISO 14001 in Brazil. Gestao e Producao, 15(1), 1-10.

Price, Lynn, Wang, Xuejun, \& Yun, Jiang. (2010). The challenge of reducing energy consumption of the Top-1000 largest industrial enterprises in China. Energy Policy, 38(11), 6485-6498. http:// dx.doi.org/10.1016/j.enpol.2009.02.036

Sarkis, Joseph, Gonzalez-Torre, Pilar, \& Adenso-Diaz, Belarmino. (2010). Stakeholder pressure and the adoption of environmental practices: The mediating effect of training. Journal of Operations Management, 28(2), 163-176. http://dx.doi.org/10.1016/j.jom.2009.10.001

Sarkis, J., Zhu, Q., \& Lai, K. H. (2011). An organizational theoretic review of green supply chain management literature. International Journal of Production Economics, 130(1), 1-15. http://dx.doi. org/10.1016/j.ijpe.2010.11.010

Sterman, John D. (2000). Business Dynamics : Systems Thinking and Modeling for a Complex World. Irwin/McGraw-Hill. Boston, Mass, 928-928.

Sterman, John D., Oliva, Rogelio, Linderman, Kevin, \& Bendoly, Elliot. (2015). System dynamics perspectives and modeling opportunities for research in operations management. Journal of Operations Management, 39-40, 1-5. http://dx.doi.org/10.1016/j.jom.2015.07.001

Stevens, P. A., Batty, W. J., Longhurst, P. J., \& Drew, G. H. (2012). A critical review of classification of organisations in relation to the voluntary implementation of environmental management systems. Journal of Environmental Management, 113, 106-212. http://dx.doi.org/10.1016/j. jenvman.2012.08.037

Sultan, F., Farley, J.U., \& Lehmann, D. R. (1990). A meta-analysis of applications of diffusion models. Journal of Marketing Research, 27(1), 70-77.

Testa, F., Boiral, O., \& Iraldo, F. (2018). Internalization of environmental practices and institutional complexity: Can stakeholders pressures encourage greenwashing? Journal of Business Ethics, $147(2)$, 287-307. http://dx.doi.org/10.1007/s10551-015-2960-2

Villena, Verónica H., \& Gioia, Dennis A. (2018). On the riskiness of lower-tier suppliers: Managing sustainability in supply networks. Journal of Operations Management. https://doi.org/10.1016/j. jom.2018.09.004

Wu, T., Daniel, E. M., Hinton, M., \& Quintas, P. (2013). Isomorphic mechanisms in manufacturing supply chains: A comparison of indigenous Chinese firms and foreign-owned MNCs. Supply Chain Management, 18(2), 161-177. http://dx.doi.org/10.1108/13598541311318809

Yang, M., \& Hyland, M. A. (2012). Re-examining mimetic isomorphism: Similarity in mergers and acquisitions in the financial service industry. Management Decision, 50(6), 1076-1095. http:// dx.doi.org/10.1108/00251741211238346

Zhu, Q., \& Sarkis, J. (2007). The moderating effects of institutional pressures on emergent green supply chain practices and performance. International Journal of Production Research, 45(18-19), 4333-4355. http://dx.doi.org/10.1080/00207540701440345 
BBR

17

600

Zhu, Q., Tian, Y., \& Sarkis, J. (2012). Diffusion of selected green supply chain management practices: An assessment of Chinese enterprises. Production Planning and Control, 23(10-11), 837-850. http://dx.doi.org/10.1080/09537287.2011.642188

Zhu, Q., Sarkis, J., \& Lai, K-H. (2008). Confirmation of a measurement model for green supply chain management practices implementation. International Journal of Production Economics, 111(2), 261-273. https://doi.org/10.1016/j.ijpe.2006.11.029

\section{AUTHOR'S CONTRIBUTION}

CR - The author idealized the study and contributed to the definition of study objective, literature searching, study designing, data collection, data analysis, data interpretation. The author was involved in drafting the article and revising it critically.

LB - The author contributed to the definition of study objective, literature searching, study designing, data collection, data analysis, data interpretation. The author was involved in drafting the article and revising it critically.

LC - The author was involved in drafting the article and revising it critically.

MU - The author was involved in revising the draft as well as the model equations.

\section{FINANCIAL SUPPORT}

The authors thank the National Council for Scientific and Technological Development (CNPq) and the Coordination for the Improvement of Higher Education Personnel (CAPES) for financial support. 